\title{
KẾT QUẢ PHẪU THUÂTT NộI SOI TÁI TẠO ĐỒNG THỜI DÂY CHẰNG CHÉO TRƯớC VÀ CHÉO SAU BẰNG KỸ THUÂT ALL-INSIDE SỬ DỤNG MẢNH GHÉP GÂN BÁN GÂN VÀ MÁC DÀI TỰ THÂN
}

\section{TÓM TẮT}

Tổn thương đồng thời dây chằng chéo trước và dây chằng chéo sau thường gặp trong bệnh cảnh tổn thương đa dây chằng, được gây ra bởi lực chấn thương năng, có thể kèm theo trâtt khớp gối. Tổn thương đa dây chằng cần đánh giá tổn thương đây đủ, phục hồi sớm các dây chằng bị tổn thương. Mục tiêu: Đánh giá kết quả phẫu thuật nội soi tái tạo đồng thời dây chẳng chéo trước và dây chằng chéo sau bằng kỹ thuật all-inside sử dụng mảnh ghép gân bán gân và gân mác dài tự thân. Đối tượng và phương pháp nghiên cứu: mô tả tiến cứu trền 32 bệnh nhân tổn thương đồng thời dây chằng chéo trước và dây chằng chéo sau, được phẩu thuật nội soi tái tạo đồng thời dây chằng chéo trước và dây chằng chéo sau bằng kỹ thuật all-inside sử dụng mảnh ghép gân bán gân và gân mác dài tự thân cùng bên. Kết quả: trong 32 bệnh nhân, tuổi trung bình 35, thời gian theo dối trung bình 15 tháng (11-23 tháng), có 28/32 bệnh nhân có biên độ vận động khớp gối bình thường, 2 trường hợp mất duỗi dưới $5^{0}$. Sau mổ tỷ lệ âm tính $(0+, 1+)$ với các dấu hiệu Lachman trước/sau là $97 \% / 100 \%$, ngăn kéo trước/sau là $97 \% / 94 \%$. Điểm Tegner và Lysholm tăng trung bình từ 3 và 52 lên 7 và 85. Kết luận: Tái tạo đồng thời dây chằng chéo trước và chéo sau bằng kỹ thuật all-inside sư dụng mảnh ghép gân cơ bán gân và gẩn mác dài tự thân là phương pháp an toàn, hiệu quả, tiết kiệm chi phí, sớm phục hồi chức năng chi cho người bệnh.

Tư khoá: Nội soi khớp, dây chằng chéo, gân cơ bán gân, gân mác dài

\section{SUMMARY \\ OUTCOME OF SIMULTANEOUS \\ ARTHROSCOPIC ANTERIOR CRUCIATE LIGMENT AND POSTERIOR CRUCIATE LIGAMENT RECONSTRUCTION WITH HAMSTRING TENDON AND PERONEUS LONGUS TENDON AUTOGRAFT}

Background: Multiligamentous injuries of knee are a complex problem in orthopaedics. Combined ACL-PCL injuries are uncommon, usually associated with knee dislocations. These complex injuries require a systematic evaluation and treatment. Objectives: To evaluate functional outcome of simultaneous

\footnotetext{
${ }^{1}$ Trường Đại Học Y Hà Nội

2 Bệnh viện HN Việt Đức

Chịu trách nhiệm chính: Dương Đình Toàn

Email: duongdinhtoan@hmu.edu.vn

Ngày nhận bài: 11.5 .2021

Ngày phản biện khoa học: 28.6.2021

Ngày duyệt bài: 12.7.2021
}

\section{Dương Đình Toàn ${ }^{1,2}$, Lê Mạnh Sơn²}

arthroscopic $\mathrm{ACL}$ and $\mathrm{PCL}$ reconstruction with semitendinosus and partial peroneus longus tendon autograft in multiligamentous knee injuries. study was performed on 32 patients with combined $A C L-P C L$ injuries who underwent simultaneous arthroscopic ACL-PCL reconstruction with semitendinosus and partial peroneus longus tendon. Evaluation of functional outcome was by IKDC and Lysholm scores. Results: In 32 patients, mean age 35 years, return to full-time work and to full sports was 9,5 weeks and 9,7 months respectively. 28/32 patients had full range of motion, 4 patients with $<5$ degrees exion loss; 89\% had negative Lachmann test; $93 \%$ had negative pivot shift and $11 \%$ patients had mild posterior drawer. Mean IKDC score was 88 (7992; mean Lysholm knee score was 85 (73-90). 85\% returned to preinjury activity. Conclusions: Simultaneous arthroscopic ACL and PCL reconstructions using semitendinosus and partial peroneus longus tendon for combined $A C L$ and $P C L$ injuries is a procedure with better patient compliance and reproducible for a timely return of motion, strength, and function with favorable outcome.

Keywords: Arthroscopic, Simultaneous ACL/PCL Reconstruction, Cruciate

\section{I. ĐĂT VẤN ĐỀ}

Khớp gối là khớp chịu lực lớn nhất cơ thể, do vật cũng là khớp dễ bị chấn thương nhất. Tổn thương đồng thời dây chằng chằng chéo trước (DCCT) và dây chằng chéo sau (DCCS) không phổ biến, thường gặp sau một chấn thương mạnh, kèm theo trật khớp gối, tỷ lệ này gặp khoảng 0,02-0,2\% trong số các loại chấn thương $[1,2]$. Ngoài tổn thuơng đa dây chằng ra còn có thể tổn thương mạch máu thân kinh, gẫy xương kèm theo, do vậy điêu quan trọng là đánh giá đầy đủ và chính xác các cấu trúc bị tổn thương sớm và điêu trị tích cực, bao gôm cả phục hồi chức năng, để người bệnh sớm quay trở lại công việc và thể thao một cách tốt nhất có thể. Trên thực tế, tỷ lệ chấn thương đa dây chằng so với các tổn thương các dây chằng đơn lẻ là thấp, do vậy đấn đề điều trị vẫn còn nhiều quan điểm khác nhau. Trước đẩy, tổn thương đa dây chằng đa số được điêu trị băo tồn bằng bất động (bột) trong thời gian dài dẫn đến teo cơ, cứng khớp, giảm chức năng khớp gối [3]. Ngày nay với sự ra đời của phẫu thuật nội soi khớp cũng như các phương tiện phẫu thuật, phương pháp phẫu thuật sửa chữa hoặc tái tạo lại các dây chằng là 
lựa chọn tất yếu [4]. Trong phẫu thuật tái tạo hai dây chằng, sử dụng mảnh ghép gân đồng loại được nhiều tác giả ưa chuộng bởi giảm thời gian phẫu thuật, mảnh ghép đủ chiều dài và đường kính, tuy nhiên nhược điểm của mảnh ghép gân đồng loại là tăng giá thành, làm chậm quá trình tái cấu trúc dây chằng mới cũng như những lo ngại về các bệnh truyền nhiểm từ người cho, mặt khác không phải lúc nào cũng có nguồn gân vì vậy sử dụng mảnh ghép tự thân từ gân Hamstring hoặc và gân mác dài vẫn là lựa chọn phổ biến.

\section{II. ĐỐI TƯợNG VÀ PHƯƠNG PHÁP NGHIÊN CỨU}

Gồm những bệnh nhân tuổi từ tổn thương DCCT và DCCS cùng một khớp gối, được phẫu thuật tái tạo đồng thời $\mathrm{DCCT}$ và $\mathrm{DCCS}$ bằng mảnh ghép gân cơ bán gân và bán phần gân cơ mác dài cùng bên tại bệnh viện Việt Đức, từ tháng $1 / 2019$ đến $1 / 2021$

\subsection{Tiêu chuẩn lựa chọn}

- Gồm những bệnh nhân tuổi từ 18-50 tổn thương đồng thời DCCT và DCCS trên cùng một khớp gối, được chẩn đoán xác định bằng lâm sàng và $M R I$

- Thời gian từ khi chấn thương đến khi phẫu thuật > 4 tuần, có biên độ vận động gối tốt.

\subsection{Tiêu chuẩn loại trừ}

- Kèm theo các tổn thương phối hợp như góc sau ngoài, tổn thương hoàn toàn dây chằng bên trong, dây chằng bên ngoài, gãy xượng, tổn thương mạch máu, thần kinh

- Có bằng chứng viêm nhiễm vùng gối

- Tổn thương dưới 3 tuần hoặc biên độ vận động gối còn hạn chế

\subsection{Thời gian nghiên cứu: $1 / 2019-1 / 2021$}

2.4 Kỹ thuật mổ

- Bệnh nhân gây tê tuỷ sống

- Đánh giá lại các tổn thương dây chằng sau gây tê

- Nội soi khớp gối với 3 ngõ vào: trước trong, trước ngoài và sau trong

- Đánh giá tổn thương DCCT, DCCS

- Lây gân cơ bán gân và bán phần gân cơ mác dài, tết gân. Gân có kích thước to hơn sẽ ưu tiên làm mảnh ghép cho DCCS

- Dọn di tích điểm bám DCCT và DCCS. Đối với DCCS sử dụng phối hợp ngõ vào sau trong

- Khoan tạo đường hầm mâm chầy, lồi câu đùi cho hai mảnh ghép theo kỹ thuật tất cả bên trong (all-insde)

- Luồn mảnh ghép theo thứ tự ưu tiên DCCS trước

- Cố định mảnh ghép bằng tightrope hai đầu

- Siết căng mảnh ghép: DCCS ở tư thế gố gấp $90^{\circ}$, DCCS tư thế gối gấp $30^{\circ}$

- Khâu da cân, đóng vết mổ

- Sau mổ: tập phục hồi chức năng theo một protocal thống nhất. Đeo nẹp 4 tuần.

\section{5. Đánh giá kết quả}

- Kết quả gần: tình trạng vết mổ, phù nề, tràn dich khớp

- Kết quả xa: theo thang điểm Tegner và Lysholme

\section{KẾT QUẢ NGHIÊN CỨU}

\section{1 Đặc điểm chung}

Bảng 1. Phân bố đặc điểm chung

\begin{tabular}{|c|c|}
\hline Các biến & Giá trị \\
\hline Giới: Nam/nữ & $27 / 5$ \\
\hline Tuối: & $35(18-50)$ \\
\hline $\begin{array}{c}\text { Nguyên nhân: Tai nạn thể } \\
\text { thao/giao thông/lao động }\end{array}$ & $7 / 18 / 10$ \\
\hline Thời gian mổ (phút): & $100(90-120)$ \\
\hline Thời gian theo dõi (tháng) & $15(11-23)$ \\
\hline
\end{tabular}

3.2. Kết quả gân

- Tất cả bệnh nhân có diễn biến vết mổ bình thường

- Có 5/32 bệnh nhân khớp gối phù nề do tràn dịch sau mổ, chỉ chườm đá, không cần hút dịch

- Có 3/32 bệnh nhân sốt nhẹ trong 2 ngày sau mổ liên quan đến tràn dịch khớp

- Thời gian nằm viện trung bình 5 ngày (từ 47 ngày)

3.3. Kết quả xa. Qua thời gian theo dõi trung bình 15 tháng (11-23 tháng), trên 32 bệnh nhân được phẫu thuật nội soi tái tạo đồng thời DCCT và DCCS, kết quả thu được như sau:

Bảng 3.2. Dấu hiệu Lachman trước và sau phầu thuật $(n=32)$

\begin{tabular}{|c|c|c|c|}
\hline $\begin{array}{c}\text { Lachman } \\
\text { trước/sau }\end{array}$ & $\begin{array}{c}\text { Trước } \\
\text { mố (gối) }\end{array}$ & $\begin{array}{c}\text { Sau mố } \\
\text { (gối) }\end{array}$ & P \\
\hline $\begin{array}{c}\text { Bình thường } \\
(0+)\end{array}$ & $0 / 0$ & $15 / 17$ & \\
\cline { 1 - 2 } $\begin{array}{c}\text { Dương tính } \\
\text { độ 1 (1+) }\end{array}$ & $0 / 0$ & $16 / 15$ & \\
\cline { 1 - 3 } $\begin{array}{c}\text { Dương tính } \\
\text { độ 2 (2+) }\end{array}$ & $3 / 4$ & $1 / 0$ & \\
\cline { 1 - 3 } $\begin{array}{c}\text { Dương tính } \\
\text { độ 3 (3+) }\end{array}$ & $29 / 28$ & $0 / 0$ & \\
\hline
\end{tabular}

Nhân xét: trước mổ cả 32 bệnh nhân có dấu hiệu Lachman trước và Lachman sau dương tính $(2+)$ và (3+). Sau mổ không còn trường hợp nào dương tính (3+) với dấu hiệu Lachman trước và sau; có 1 trường hợp có Lachman trước $(2+)$ và 31/32 Lachman trước bình thường hoặc $(1+)$, cả 32 bệnh nhân Lachman sau (1+) hoặc bình thường. Sự thay đổi trước và sau mổ có ý nghĩa thống kê. 
Bảng 3.3. Dấu hiệu ngăn kéo trước trước và sau phẫu thuật ( $n=32)$

\begin{tabular}{|c|c|c|c|}
\hline $\begin{array}{c}\text { Ngăn kéo } \\
\text { trước/sau }\end{array}$ & $\begin{array}{c}\text { Trước } \\
\text { mố (gối) }\end{array}$ & $\begin{array}{c}\text { Sau mố } \\
\text { (gối) }\end{array}$ & $\mathbf{P}$ \\
\hline $\begin{array}{c}\text { Bình thường } \\
(0+)\end{array}$ & $0 / 0$ & $14 / 16$ & \\
\cline { 1 - 2 } $\begin{array}{c}\text { Dương tính } \\
\text { độ 1 (1+) }\end{array}$ & $0 / 0$ & $17 / 14$ & \\
\hline $\begin{array}{c}\text { Dương tính } \\
\text { độ 2 (2+) }\end{array}$ & $3 / 2$ & $1 / 2$ & \multirow{2}{*}{$<0,05$} \\
\cline { 1 - 3 } $\begin{array}{c}\text { Dương tính } \\
\text { độ 3 (3+) }\end{array}$ & $29 / 30$ & $0 / 0$ & \\
\hline
\end{tabular}

Nhận xét: trước mổ cả 32 bệnh nhân có dấu hiệu ngăn kéo trước và ngăn kéo sau dương tính $(2+)$ và $(3+)$. Sau mổ không còn trường hợp nào ngăn kéo $(3+)$; có 1 trường hợp có ngăn kéo trước $(2+), 2$ trường hợp ngăn kép sau $(2+)$ và $31 / 31$ ngăn kéo trước bình thường hoặc $(1+)$, cả 30/32 bệnh nhân ngăn kéo sau (1+) hoặc bình thường. Sự thay đổi trước và sau mổ có ý nghĩa thống kê.

Bảng 3.4. Điểm Tegner và Lysholm trước và sau phấu thuật $(n=32)$

\begin{tabular}{|c|c|c|c|}
\hline & Trước mổ & Sau mổ & P \\
\hline Điểm Tegner & $3(1-4)$ & $7(5-9)$ & $<$ \\
Điểm Lysholm & $51(45-64)$ & $85(80-95)$ & 0,05 \\
\hline
\end{tabular}

Nhận xét: Sau mổ điểm Tegner và Lysholm tăng lển một cách có ý nghĩa thống kê so với trước mổ

\section{BÀN LUẬN}

4.1. Đắc điểm chung. Tỷ lệ nam gặp nhiều hơn nữ (5/1), chủ yếu nguyên nhân do tai nạn giao thông và lao động. So với tổn thương dây chằng chéo trước hoặc chéo sau đơn thuần, nguyên nhân chủ yếu là tai nạn thể thao. Điều này cho thấy, tổn thương đồng thời DCCT và DCCS thường gặp trong bối cảnh lực chấn thương lớn, thường kèm theo trật khớp gối, thuộc đối tượng ở tuổi lao động. Kết quả này phù hợp với các nghiên cứu khác.

Sử dụng mảnh ghép gân cơ bán gân và bán phần cơ mác bên dài. Trong phần lớn các trường hợp tổn thương đồng thời DCCT và DCCS có kèm theo tổn thương dây chằng bên trong từng mức độ khác nhau, trong bệnh cảnh của tổn thương đa dây chằng. Vì vậy để không làm suy yếu phức hợp dây chằng làm vững khớp phía trong (bao gồm dây chằng bên trong, gân cơ chân ngỗng), chúng tôi chỉ sử dụng gân cơ bán gân làm mảnh ghép DCCT, giữ lại gân cơ thon, đồng thời sử dụng bán phần gân cơ mác dài làm mảnh ghép DCCS. Vơi hai nguồn gân này, bằng kỹ thuật allinside, mảnh ghép sau chập 4 đảm bảo đủ chiêu dài và đường kính trung bình $8,2 \mathrm{~mm}$ (nhỏ nhất là 7,5mm, lớn nhất là $8,5 \mathrm{~mm}$ ).

4.2. Kêt quả. Thời gian theo dõi trung bình 15 tháng (11-23 tháng), có 28/32 bệnh nhân có biên độ vận động khớp gối bình thường, 2 trường hợp mất duỗi dưới $5^{0}$. Sau mổ tỷ lệ âm tính $(0+, 1+)$ với các dấu hiệu Lachman trước/sau là 97\%/100\%, ngăn kéo trước/sau là $97 \% / 94 \%$. Điểm Tegner và Lysholm tăng trung bình từ 3 và 52 lên 7 và 85 . Theo Wascher và cộng sự, báo cáo 13 bệnh nhân (trong đó 9 tổn thương cấp tính, 4 tổn thương cũ) tái tạo đồng thời DCCT và DCCS bằng mảnh ghép gân Achills hoặc gân bánh chè đồng loại thì gặp 6 trường hợp bất thường về phân loaik IKDC [5]. Hay Mariani và cộng sự theo dõi trên 15 trường hợp nội soi tái tạo đồng thời $\mathrm{DCCT}$ và DCCS bằng mảnh ghép gân Hamstring và gân bánh chè tự thân, đánh giá bằng thang điểm IKDC, có 7 trường hợp mức $B, 3$ trường hợp mức $C$ và 1 trường hợp mức $D[6]$. Một nghiên cứu khác của Fanelli và Edson đánh giá trên 35 bênh nhân sử dụng vừa gân tự thân vừa gân đồng loại, ghi nhận $45 \%$ test ngăn kéo sau bình thường, $94 \%$ test Lachman bình thường [7].

Mảnh ghép gân tự thân và đồng loại đều có thể sử dụng để tái tạo đồng thời cả hai dây chằng. Ưu điểm của gân đồng loại là giảm thời gian phẫu thuật (không phải lấy gân), tăng kích thước cho mảnh ghép, tuy nhiên nhược điểm của loạ gân này là tăng nguy cơ nhiễm trùng, tăng chi phí và đăc biêt là trì chậm quá trình tái cấu trúc đây chằng từ mảnh ghép và có thể lây nhiễm chéo một số bệnh nếu quá trình xử lý mảnh ghép khồng tốt. Đối với mảnh ghép tự thân, ưu điểm lớn nhất là tính an toàn và thúc đẩy nhanh hơn quá trình tái cấu trúc dây chằng từ mảnh ghép.

Các nghiên cưu đều kết luận rằng, phẫu thuật tái tạo đồng thời hai dây chằng chéo bằng mảnh ghép tự thân đều mang lại kết quả thành công, an toàn, giảm chi phí.

\section{KẾT LUÂN}

Sau mổ với 28/32 bệnh nhân có biên độ vận động khớp gối bình thường, 2 trường hợp mất duỗi dưới 50 . Sau mổ tỷ lệ âm tính $(0+, 1+)$ với các dấu hiệu Lachman trước/sau là $97 \% / 100 \%$, ngăn kéo trước/sau là 97\%/94\%. Điểm Tegner và Lysholm tăng trung bình từ 3 và 52 lên 7 và 85. Qua đó chung tôi thấy, phẫu thuật tái tạo đồng thời dây chằng chéo trước và chéo sau bằng kỹ thuật all-inside sử dụng mảnh ghép gân cơ bán gân và gân mác dài tự thân là phương 
pháp an toàn, hiệu quả, tiết kiệm chi phí, sớm phục hồi chức năng chi cho người bệnh.

\section{TÀI LIẸU THAM KHẢO}

1. Johansen $S$. Outcome after knee dislocations: a 2-9 years follow-up of 85 consecutive patients. Knee Surg Sports Traumatol Arthrosc. 2009;17(9):1013-26.

2. Klimkiewicz JJ, Petrie RS, Harner CD. Surgical treatment of com- bined injury to anterior cruciate ligament, posterior cruciate liga- ment, and medial structures. Clin Sports Med. 2000;19(3):479-92.

3. Liow RY, McNicholas MJ, Keating JF, Nutton RW. Ligament repair and reconstruction in traumatic dislocation of the knee. J Bone Joint Surg Br. 2003;85(6):845-51.

4. Wong CH, Tan JL, Chang HC, Khin LW, Low Co. Knee dislocations-a retrospective study comparing operative versus closed immobi- lization treatment outcomes. Knee Surg Sports Traumatol Arthrosc. 2004;12(6):540

5. Wascher DC, Becker JR, Dexter JG, Blevins FT. Reconstruction of the anterior and posterior cruciate ligaments after knee disloca- tion. Results using fresh-frozen nonirradiated allografts. Am J Sports Med. 1999;27(2):189-96.

6. Mariani PP, Margheritini F, Camillieri G. Onestage arthroscopi- cally assisted anterior and posterior cruciate ligament recon- struction. Arthroscopy. 2001;17(7):700-7. U, Wippermann B, Hofmann A, K

7. Fanelli GC, Edson Cj. Conbined $\mathrm{PCL}$ posterolateral reconstructions with Achilles tendon allograft and biceps femoris tendon tenodesis: 2to 10-year follow-up. Arthros- copy. 2004; 20(4): $339-45$.

\section{MộT Số YẾU Tố LIÊN QUAN ĐẾN CHẤP NHÂ̂N TIÊM VẮC XIN PHÒNG COVID-19 CỦA GIÁO VIÊN VIÊTT NAM NĂM 2021}

\section{TÓM TẮT}

Nghiên cứu mô tả cắt ngang trên 1902 giáo viên ở Việt Nam có độ tuổi từ 18- 59 từ ngày 15/5/2021 đến $16 / 6 / 2021$. Mục tiêu nghiên cứu nhằm xác định tỷ lệ và môt số yếu tố liên quan đến chấp nhân tiêm vắc xin phòng COVID-19 của giáo viên Việt Nam. Kết quả: tỷ lệ đối tượng nghiên cứu chấp nhân tiêm vắc xin là $85,9 \% ; 69,1 \%$ săn sàng trả tiền tiểm vắc xin. Các yếu tố liên quan đến tỷ lệ chấp nhân tiêm vắc xin là nhóm tuổi từ 40 đến 49 tuổi và từ 50 đến 59 tuổi sẵn sàng tiêm vắc xin gấp 2,05 lần và 2,67 lần so với nhóm từ $18-29$ tuổi $(p<0,001)$, giáo viên cấp THCS và THPT tỷ lệ chấp nhận tiêm ít hơn so với nhóm giáo viên mầm non $(\mathrm{p}<0,001)$, nhóm giáo viên có gia đình sẵn sàng tiêm vắc xin gấp 2,21 lần so với nhóm còn độc thân $(p<0,001)$, tình trạng mắc bệnh mạn tính làm giảm tỷ lệ chấp nhận tiêm vắc xin $(p<0,001)$; chưa tìm thây sư khác biêt về viêc chấp nhân tiêm phòng vắc xin COVID-19 giữa thành phố và nông thôn, nhóm nam và nữ, giữa người dân tộc Kinh với những người dân tộc khác. Kết luận: kết quả nghiên cứu cho thây tỷ lệ giáo viên chấp nhận tiêm vắc xin cao, đa số châp nhận chi trả cho việc tiêm vắc xin. Các yếu tố liên quan đến tỷ lệ chấp nhận tiêm vắc xin có ý nghĩa là nhóm tuổi, cấp giảng dạy, tình trạng hôn nhân và tình trạng mắc bệnh mạn tính.

\footnotetext{
${ }^{1}$ Trường Đại học Y tế Công cộng

${ }^{2}$ Trường Đại học Kinh tế Quốc dân

Chiu trách nhiệm chính: Nguyễn Thị Hà

Email: nth16@huph.edu.vn

Ngày nhận bài: 14.5.2021

Ngày phản biên khoa họ: 1.7.2021

Ngày duyệt bài: 12.7.2021
}

Nguyễn Thị Hà ${ }^{1}$ Đặng Thị Huê², Phạm Hùng Tiến', Nguyễn Thị Anh Vân ${ }^{1}$

Từ khóa: Vắc xin phòng COVID-19; chấp nhận tiêm vắc xin; giáo viên Việt Nam.

\section{SUMMARY \\ SOME FACTORS ASSOCIATED WITH \\ ACCEPTANCE OF COVID-19 VACCINE \\ AMONG VIETNAMESE TEACHERS}

A cross-sectional web-based study was conducted from May 15, 2021 to June 16, 2021. The study participants included 1902 Vietnamese teachers, between 18 and 59 years old. The objective of the study was to determine the rate and some factors associated with acceptance of COVID-19 vaccine among Vietnamese teachers. Results: $85.9 \%$ of the participants accepted vaccination; $69.1 \%$ confirmed their willingness to pay for vaccination. Some factors as age, being a secondary school teacher, marital status, post-graduate education, and chronic diseases are the related factors to their vaccination acceptance; no difference was found between city and countryside, between male and female teachers, between Kinh and other ethnic groups in terms of their acceptance of COVID-19 vaccination.

Keywords: COVID-19 vaccine; vaccination acceptance; Vietnamese teachers.

\section{I. ĐĂT VẤN ĐỀ}

Dich bênh COVID-19 lần đầu tiên được báo cáo ở Vũ Hán-Trung Quốc vào ngày 31 tháng 12 năm 2019 [1]. Cho đến nay, dịch COVID-19 đã lan ra toàn cầu với số lượng người tử vong rất cao. Thống kê đến ngày $21 / 7 / 2021$, trên thế giới có 188.655.968 người mắc COVID-19 với tổng số ca tử vong là 4.067.517 [2]. Tại Việt Nam, vào 